\title{
СОГЛАШЕНИЕ КАК ФОРМА НАЛОГОВОГО МОНИТОРИНГА
}

Аннотация. Федеральным законом от 4 ноября 2014 года в Налоговый кодекс Российской Федерации введен новый раздел V.2 «Налоговый контроль в форме налогового мониторинга». В настоящей статье автор анализирует введенную не так давно в налоговое законодательство категорию «налогового мониторинга». Основными целями работы являются определение понятия такой формы налогового контроля как "налоговый мониторинг», а также ответ на вопрос "в какой правовой форме должны реализовываться отношения по налоговому мониторингу между налоговым органом и налогоплательщиком?» В работе автор анализирует историю принятия закона, являющегося предметом исследования, нормы налогового кодекса и иные нормы налогового законодательства, а также научной литературы, иные нормы действующего налогового законодательства, а также обращается к опыту зарубежного законодательства. Автором дается собственное определение налогового мониторинга. Автор делает вывод о том, что наилучшей формой налогового мониторинга является заключение соглашения о расширенном информационном взаимодействии. Автор приводит обоснование того почему именно соглашение о расииренном информационном взаимодействии является более последовательным и обоснованным решением.

Ключевые слова: соглашение, договор, налоговое право, оперативный налоговый аудит, форма налогового контроля, налог, налоговый мониторинг, информация, информационное взаимодействие, налоговый контроль.

Review. The Federal Law of 4.11.2014 introduced a new chapter into the Tax Code of the Russian Federation - V.2 "Tax Control in the Form of Tax Monitoring". The author of this article analyzes the recently introduced category of "tax monitoring". The work is aimed at defining the notion of tax monitoring and at answering the question "In what form should tax monitoring relations between a taxation authority and a taxpayer be realized?". The author analyzes the history of the Law at issue adoption, the Tax Code norms and provisions of tax legislation, scientific literature, other norms of the existing tax legislation; the author also considers the experience of foreign legislation. The author offers her own definition of tax monitoring. The author concludes that an agreement on enhanced information cooperation is the best form of tax monitoring and substantiates this conclusion.

Key words: information, tax monitoring, tax, form of tax control, real-time tax audit, tax law, contract, agreement, information cooperation, tax control.

$\Phi$ едеральным законом от 4 ноября 2014 года в Налоговый кодекс Российской Федерации введен новый раздел V.2 «Налоговый контроль в форме налогового мониторинга» [1].

В соответствии с пунктом 1 статьи 105.26. Налогового кодекса РФ предметом налогового мониторинга являются правильность исчисления, полнота и своевременность уплаты (перечисления) налогов и сборов, обязанность по уплате (перечислению) которых в соответствии с настоящим Кодексом возложена на налогоплательщика (плательщика сбора, налогового агента) - организацию [2].

Как отмечается в пояснительной записке к законопроекту суть проекта заключается в том, что налогоплательщик еще до подачи налоговой декларации может разрешить спорные вопросы налогообложения [3]. В свою очередь, налоговый орган в режиме реального времени получает доступ к данным бухгалтерского и налогового учета налогоплательщика и может проверять правильность и своевременность отражения хозяйственных операций налогоплательщиком для целей налогообложения.

Данный вид налогового администрирования, по мнению разработчиков закона, не только соответствует мировым практиками (США, Великобритания, Нидерланды и др.), но и позволяет более оперативно и качественно осуществлять ФНС России функции по контролю и надзору за соблюдением законодательства о налогах и сборах, за правильностью исчисления, полнотой и своевременностью внесения в соответствующий бюджет налогов и сборов. 
Одними из первых институт горизонтального мониторинга в свое законодательства ввели Нидерланды. В 2005 году Налоговая и таможенная администрация Нидерландов инициировала программу «Горизонтальный мониторинг», с участием 20 крупнейших предприятий. После положительных отзывов участвующих предприятий, программа была распространена также на малые и средние предприятия [4].

Концепция налогового аудита в режиме реального времени, применяемая в Соединенных штатах Америки (real-time tax audit) в некоторых отношениях опирается на исторические корни. Начиная с времен гражданской войны с наложением налога на прибыль государство оказывало услуги аудита прибыли до ее декларирования [5]. Это программа добровольного участия налогоплательщика в проверке Внутренней налоговой службой соответствия осуществляемой деятельности требованиям налогового законодательства (САР) а также разъяснения норм налогового законодательства в соответствии с Финансовым разъяснением № 48 (FIN 48) [6].

Горизонтальный мониторинг или аудит в реальном времени был внедрен также и в Великобритании. Тогда из налоговых органов была выведена отдельная структура, а сам проект имел цель изменить отношения между чиновниками и бизнесом, сформировать доверие между сторонами. Изначально эксперимент носил добровольный характер, однако в 2008 году был принят финансовый акт, который нормализовал процедуры подачи налоговой информации. Получив широкое распространение, система закрепила публичное мнение, что налогоплательщику выгоден статус low risk, так как этот статус предусматривает уменьшение количества проверок бизнеса со стороны налоговых служб [7].

Ирландская модель горизонтального мониторинга получила название Объединения в целях совместного соблюдения налогового законодательства (Cooperative Compliance program). Данная программа включает в себя добровольные договоренности между отдельными крупными предприятиями и налоговой службой, о том, что каждая сторона должна сделать для того, чтобы бизнес действовал в рамках налогового законодательства и мог получать оперативные разъяснения относительно толкования тех или иных норм налогового права [8].

Принятию указанного закона предшествовал большой эксперимент налоговых органов в части введения налогового мониторинга в отношении ряда крупных компаний, действующих на территории Российской Федерации.

Так, по официальной информации Федеральной налоговой службы 25 декабря 2012 года в зда- нии Федеральной налоговой службы состоялось подписание четырех соглашений о расширенном информационном взаимодействии - горизонтальном мониторинге между ФНС России и компаниями - крупнейшими налогоплательщиками: ОАО «Русгидро», ОАО «ИНТЕР РАО ЕЭС», ОАО «Мобильные ТелеСистемы» и Компанией «Эрнст энд Янг (СНГ) Б.В.». В рамках заключенных двусторонних соглашений налоговый орган обязался осуществлять мониторинг финансово-хозяйственных операций налогоплательщиков в режиме реального времени, а компании получили возможность заранее согласовывать свою позицию по вопросам налогообложения с ФНС России [9].

Заключение в 2012 году указанных соглашений вызвало неоднозначное мнение среди ученых и практиков в сфере налогового права. Так, А.В. Брызгалин, указывал на то, что фактически в 2012 году налоговыми органами допущено заключение неких соглашений, не предусмотренных нормами действующего налогового законодательства. Кроме того, как полагал А.В. Брызгалин, заключение соглашений, предусматривающих освобождение от внезапных налоговых проверок противоречит действующему законодательству, а в частности главе 14 Налогового кодекса РФ [10].

В свою очередь Н.А. Саттарова подчеркивает, что при всей очевидности положительных сторон данного института следует указать, что эффективность данного способа взаимодействия участников налоговых правоотношений возможна только при определенных условиях. Например, осуществление налоговым органом процедуры отслеживания финансово-хозяйственных операций возможно только в отношении добросовестных налогоплательщиков. Причем не всякий добросовестный налогоплательщик может заключить указанное соглашение. Кроме того, можно ли рассчитывать налогоплательщику на оперативность и своевременность реагирования налоговых органов на возникшие вопросы со стороны налоговых органов, если горизонтальный мониторинг предполагает консультирование в режиме реального времени [11].

Одновременно ученые отмечали и положительные стороны заключения таких соглашений.

А.Ю. Ильин указывает на то, что данный метод должен быть направлен на дальнейшее доверительное взаимоотношение налоговых органов и налогоплательщиков, на новый уровень общения с налогоплательщиками. Целью горизонтального мониторинга должно стать предупреждение осуществления налогоплательщиком рисковых операций и определение причин, предопределяющих их, налоговое консультирование, разрешение налоговых споров в досудебном порядке [12]. 


\section{Административное и муниципальное право 12 (96) • 2015}

Н.А. Саттарова также полагает, что что развитие информационного обмена в налоговой сфере, совершенствование процесса горизонтального мониторинга должно гармонизировать и без того сложные отношения в сфере налогообложения [11].

Рассмотрения заслуживает вопрос об определении понятия налогового мониторинга, поскольку законодательство такого не содержит. Как было отмечено выше Налоговый кодекс РФ определяет лишь предмет налогового мониторинга. Юридическая наука на сегодняшний день не сформировала позиции относительно данного вопроса. Представители же экономической науки предлагают следующие дефиниции.

В.В.Гензель полагает, что горизонтальный (налоговый) мониторинг - это осуществление налоговым органом процедуры отслеживания и анализа налоговых рисков по финансово-хозяйственным операциям, проведенным и запланированным крупными налогоплательщиками [13].

Л.А.Чистякова определяет налоговый мониторинг как одну из форм налогового контроля в РФ, при которой осуществляется проверка правильности исчисления, полноты и своевременности уплаты (перечисления) налогов и сборов, обязанность по уплате (перечислению) которых, в соответствии с НК РФ, возложена на налогоплательщика (плательщика сбора, налогового агента) - организацию [14].

В то же самое время Е.Г.Весницкая определяет его как специальную форму налогового контроля, которая реализуется посредством электронного информационного взаимодействия между хозяйствующим субъектом и налоговым органом [15]

Спор о соотношении форм и методов налогового контроля имеет место быть в науке налогового права уже достаточно длительное время. В налоговом законодательстве на сегодняшний день также нет четкого разграничения форм и методов налогового контроля. Под формами налогового контроля законодатель предлагает понимать и методы, формулируя статью 82 НК Российской Федерации «Общие положения о налоговом контроле» следующим образом: «налоговый контроль проводится должностными лицами налоговых органов в пределах своей компетенции посредством налоговых проверок, получения объяснений налогоплательщиков, налоговых агентов и плательщиков сбора, проверки данных учета и отчетности, осмотра помещений и территорий, используемых для извлечения дохода (прибыли), а также в других формах, предусмотренных настоящим Кодексом» [16].

Традиционно под к формам налогового контроля принято относить учет налогоплательщиков; налоговые проверки; контроль налоговых поступлений (оперативный налоговый контроль); контроль за соответствием расходов налогоплательщиков их доходам; проверка данных учета и отчетности. Все остальные действия, перечисленные в статье 82 Налогового кодекса РФ, как то получения объяснений налогоплательщиков, налоговых агентов и плательщиков сбора, проверки данных учета и отчетности, осмотра помещений и территорий, используемых для извлечения дохода (прибыли) и другие, являются методами налогового контроля.

Таким образом, несмотря на законодательное закрепление налогового мониторинга как формы налогового контроля необходимо определить, чем же он является на самом деле: формой или методом налогового контроля. Поскольку целью данного исследования не является проблема определения элементов налогового контроля, то остановимся на приведенных ниже определениях.

Под формой налогового контроля следует понимать способ конкретного выражения и организации контрольных действий, осуществляемых субъектами налогового контроля на постоянной основе всех подлежащих контролю субъектов [17].

Метод налогового контроля составляют приемы и способы, используемые при реализации той или иной формы налогового контроля, в зависимости от конкретных обстоятельств [17].

Анализ глав 14.7 и 14.8 Налогового кодекса РФ позволяют прийти к выводу о том, что проведение налогового мониторинга предполагает применение различных методов, в числе которых: истребование у организации необходимых документов (информации), пояснений, связанных с правильностью исчисления (удержания), полнотой и своевременностью уплаты (перечисления) налогов и сборов, составление и направление мотивированного мнения налогового органа, и другие.

Указанное выше обстоятельство, а также системный анализ пункта 1 статьи 105.26 Налогового кодекса РФ, в котором определен предмет налогового мониторинга, и пункта 4 статьи 89 Налогового кодекса РФ, который определяет, что правильность исчисления и своевременность уплаты налогов является предметом выездной налоговой проверки, позволяют прийти к выводу о том, что налоговый мониторинг является формой налогового контроля.

На основании изложенного, можно сделать вывод о том, что налоговый мониторинг является формой налогового контроля, при которой осуществляется проверка правильности исчисления, полноты и своевременности уплаты (перечисления) налогов и сборов, обязанность по уплате (перечислению) которых, в соответствии с НК РФ, возложена на налогоплательщика (плательщика сбора, налогового агента) - организацию, посред- 
ством истребования у организации необходимых документов (информации), пояснений, связанных с правильностью исчисления (удержания), полнотой и своевременностью уплаты (перечисления) налогов и сборов, составления и направления мотивированного мнения налогового органа, и взаимосогласительных процедур.

Здесь следует обратить внимание на то обстоятельство, что несмотря апробацию института налогового контроля на протяжении 2012-2014 годов в форме заключения соглашений о расширенном информационном взаимодействии - горизонтальном мониторинге, в окончательной редакции закона введена в действия совершенно иная процедура.

Первоначальная редакция проекта Федерального закона № 529630-6 «0 внесении изменений в часть первую Налогового кодекса Российской Федерации» (в части введения института налогового мониторинга), внесенная на рассмотрение Государственной Думы ФС РФ в мае 2014 года, предусматривала в разделе V.2. главу 14.7. под названием «Соглашение о расширенном информационном взаимодействии. Порядок заключения соглашения» [18]. Указанная глава предусматривала определение такого соглашения, его условия и правовой статус сторон, порядок его заключения и прекращения и другие условия. В такой редакции законопроект прошел первое чтение в законодательном органе.

Однако ко второму чтению проекта закона о кардинально изменился в части регламентации формы налогового мониторинга. Нормы о возможности заключения соглашений пропали, законодатель решил пойти по пути так называемого «заявительного» механизма. Глава 14.7. в итоговой редакции получила наименование «Налоговый мониторинг. Регламент информационного взаимодействия» [19]. А вступить в отношения по налоговому мониторингу налогоплательщик, может обратившись в налоговый орган с заявлением о проведении налогового мониторинга, по итогам рассмотрения которого налоговым органом будет вынесено решение о проведении налогового мониторинга. Вместе с заявлением налогоплательщиком по установленной форме в налоговый орган предоставляется регламент информационного взаимодействия, который и определяет впоследствии порядок проведения налогового мониторинга.

Одновременно следует отметить, что заключения, содержащиеся в паспорте законопроекта, не содержат каких-либо замечаний в части необходимости отхода от механизма заключения соглашений [20].

Полагаем, что заключение соглашений о расширенном информационном взаимодействии при реализации такой формы налогового контроля как налоговый мониторинг было бы более последовательным и обоснованным нежели процедура, которая введена в текст Налогового кодекса РФ в итоговой редакции. Это заключение основывается на ряде доводов.

Во-первых, сама сущность налогового мониторинга, который также называют горизонтальным мониторингом, заключается в том, что стороны находятся не в отношениях власти и подчинения, а наоборот в «горизонтальных» отношениях, то есть «на равных».

Во-вторых, тенденции развития налогового законодательства последних лет четко показывают расширение сферы применения соглашений в налоговом праве. Здесь можно привести в пример введенные в последние годы механизмы заключения договора о создании консолидированной группы налогоплательщиков, соглашения о ценообразовании, расширение сферы применения мировых соглашений в налоговых спорах.

В-третьих, налоговое право России не содержит таких процедур, как согласование регламента взаимодействия. В соответствии с пунктом 6 статьи 105.26 Налогового кодекса РФ в регламенте информационного взаимодействия отражается порядок представления налоговому органу документов (информации), служащих основаниями для исчисления (удержания), уплаты (перечисления) налогов и сборов в электронной форме, и (или) доступа к информационным системам организации, в которых содержатся указанные документы (информация), по выбору организации. Также в регламенте информационного взаимодействия указывается порядок ознакомления налогового органа с подлинниками таких документов в случае необходимости.

Таким образом, регламент, который составляется налогоплательщиком и предоставляется в налоговый орган с заявление налогоплательщика фактически определяет правовой статус налогового органа в том числе, поскольку содержит положения регламентирующие некоторые права и обязанности налогового органа. Полагаем, что соглашение, являясь двусторонним документом, было бы более верным с позиции согласования воли двух субъектов правоотношений.

В-четвертых, зарубежный опыт налогового (горизонтального) мониторинга показывает успешность опыта применения таких соглашений в этой сфере.

Так, по нидерландской концепции горизонтального мониторинга между службой налогового и таможенного администрирования и налогоплательщиком заключается договор соответствия на основе таких ключевых ценностей взаимное дове- 


\section{Административное и муниципальное право $12(96) \cdot 2015$}

рие, понимание и прозрачность. Такой договор охватывает достаточно широкий спектр налогов [21]. Подводя итог авто приходит к следующим выводам:

1. Налоговый мониторинг является формой налогового контроля, при которой осуществляется проверка правильности исчисления, полноты и своевременности уплаты (перечисления) налогов и сборов, обязанность по уплате (перечислению) которых, в соответствии с НК РФ, возложена на налогоплательщика (плательщика сбора, налогового агента) - организацию, посредством истребования у организации необходимых документов (информации), пояснений, связанных с правильностью исчисления (удержания), полнотой и своевременностью уплаты (перечисле- ния) налогов и сборов, составления и направления мотивированного мнения налогового органа, и взаимосогласительных процедур.

2. Наилучшей формой налогового мониторинга является заключение соглашения о расширенном информационном взаимодействии. Данный вывод подтверждается сущностью двустороннего взаимодействия налогоплательщика и налогового органа при проведении налогового мониторинга, тенденциями развития налогового законодательства в части расширения сферы применения соглашений в налоговом праве, отсутствием аналогов применения механизма составления регламента как правового акта, а также зарубежным опытом налогового (горизонтального мониторинга).

\section{Библиография:}

1. 0 внесении изменений в часть первую Налогового кодекса Российской Федерации: федер. закон от 04.11.2014 № 348-Ф3 // Собрание законодательства РФ. 2014. № 45. Ст. 6158.

2. Налоговый кодекс Российской Федерации (часть первая) от 31.07.1998 № 146-Ф3.

3. К проекту Федерального закона «О внесении изменений в часть первую Налогового кодекса Российской Федерации»: пояснительная записка // Доступ из справочной правовой системы «КонсультантПлюс».

4. Enhanced Relationship with the Dutch Tax and Customs Administration. URL: http://www.tradeandtax.com/en/ enhanced-relationship/ (дата обращения: 27.05.2015).

5. Real Time Tax System Initiative: comments of T. Keith Fogg, Director, Villanova Law School Federal Tax Clinic. URL: http:// www.irs.gov/pub/irs-utl/t._keith_fogg_aba_tax_section_and_low_income_tax_clinic.pdf (дата обращения: 27.05.2015).

6. Beck Paul J., Lisowsky P. Tax Uncertainty and Voluntary Real-Time Tax Audits. URL: http://aaajournals.org/doi/ abs/10.2308/accr-50677 (дата обращения: 27.05.2015).

7. Двигаясь в едином русле // Российская газета. 2013. 21 мая. URL: http://www.rg.ru/2013/05/21/pravo.html (дата обращения: 27.05.2015).

8. The Cooperative Approach to Tax Compliance-Revenue Working with Large Business. URL: http://www.revenue.ie/en/ business/running/large-businesses.html (дата обращения: 27.05.2015).

9. Федеральная налоговая служба: сайт. URL: www.nalog.ru/html/sites/www.r28.nalog.ru/.../26.12.12.doc (дата обращения: 27.05.2015).

10. Соглашение о неком «горизонтальном мониторинге» как новая форма налогового контроля ... причем не предусмотренная действующим налоговым законодательством // О налогах и о жизни: персональный блог Аркадия Брызгалина. URL: http://www.nalog-briz.ru/2013/01/blog-post_6516.html (дата обращения: 27.05.2015).

11. Саттарова Н.А. Горизонтальный мониторинг как фактор эффективности налогового администрирования // Финансовое право. 2014. № 10. С. 24.

12. Ильин А.Ю. Горизонтальный мониторинг-новый метод в системе налогового контроля // Финансовое право. 2014. № 10. С. 5.

13. Гензель В. Практика применения горизонтального мониторинга // Налоговый вестник. 2013. № 6. С. 65.

14. Чистякова Л. Налоговый мониторинг - новая форма налогового контроля в РФ // Налоговый вестник. 2014. № 12. С. 18.

15. Весницкая Е.Г. Знакомьтесь: новая форма налогового контроля-налоговый мониторинг // Актуальные вопросы бухгалтерского учета и налогообложения. 2015. № 2. С. 64.

16. Горелов А.А. Формы и методы, используемые налоговыми органами при осуществлении мероприятий налогового контроля // Административное и муниципальное право. 2008. № 8. С. 77.

17. Налоговое право. Общая часть: учебник и практикум для академического бакалавриата / авт. колл. под. ред. И.И. Кучерова. М.: Юрайт, 2014. С. 504.

18. О внесении изменений в часть первую Налогового кодекса Российской Федерации: проект Федерального закона № 529630-6 (ред., принятая ГД ФС РФ в І чтении 01.07.2014) // Доступ из справочной правовой системы «КонсультантПлюс».

19. О внесении изменений в часть первую Налогового кодекса Российской Федерации: проект Федерального закона № 529630-6 (ред., подготовленная ГД ФС РФ ко ІІ чтению 21.10.2014) // Доступ из справочной правовой системы «КонсультантПлюс».

20. См.: По проекту Федерального закона № 529630-6 «0 внесении изменений в часть первую Налогового кодекса Российской Федерации» (первое чтение): заключение ПУ Аппарата ГД ФС РФ от 23.06.2014 № 2.2-1/3447 // Доступ из справочной правовой системы «КонсультантПлюс»; По проекту Федерального закона № 529630-6 «0 внесении изменений в часть первую Налогового кодекса Российской Федерации» (первое чтение): решение Комитета по бюджету и налогам от 27.06.2014 // Доступ из справочной правовой системы «КонсультантПлюс». 
21. Enhanced Relationship with the Dutch Tax and Customs Administration. URL: http://www.tradeandtax.com/en/ enhanced-relationship/ (дата обращения: 27.05.2015)

22. Ефремова Т.А., Ефремова Л.И. Информационное взаимодействие налоговых органов с налогоплательщиками: действующая практика и перспективы развития // Налоги и налогообложение. - 2015. - 6. - C. 457 - 464. DOI: 10.7256/1812-8688.2015.6.15265.

23. Иризепова М.Ш., Ломакина Т.П. Организация государственного налогового мониторинга России // Налоги и налогообложение. - 2014. - 5. - С. 490 - 500. DOI: 10.7256/1812-8688.2014.5.12198.

24. Е.В. Надточий Горизонтальный мониторинг - новый инструмент взаимодействия в налоговой сфере // Налоги и налогообложение. - 2013. - 1. - С. 33 - 40. DOI: 10.7256/1812-8688.2013.01.3.

\section{References (transliterated):}

1. O vnesenii izmenenii v chast' pervuyu Nalogovogo kodeksa Rossiiskoi Federatsii: feder. zakon ot 04.11.2014 № 348-FZ // Sobranie zakonodatel'stva RF. 2014. № 45. St. 6158.

2. Nalogovyi kodeks Rossiiskoi Federatsii (chast' pervaya) ot 31.07.1998 № 146-FZ.

3. K proektu Federal'nogo zakona «0 vnesenii izmenenii v chast' pervuyu Nalogovogo kodeksa Rossiiskoi Federatsii»: poyasnitel'naya zapiska // Dostup iz spravochnoi pravovoi sistemy «Konsul'tantPlyus».

4. Enhanced Relationship with the Dutch Tax and Customs Administration. URL: http://www.tradeandtax.com/en/ enhanced-relationship/ (data obrashcheniya: 27.05.2015).

5. Real Time Tax System Initiative: comments of T. Keith Fogg, Director, Villanova Law School Federal Tax Clinic. URL: http://www.irs.gov/pub/irs-utl/t._keith_fogg_aba_tax_section_and_low_income_tax_clinic.pdf (data obrashcheniya: 27.05.2015).

6. Beck Paul J., Lisowsky P. Tax Uncertainty and Voluntary Real-Time Tax Audits. URL: http://aaajournals.org/doi/ abs/10.2308/accr-50677 (data obrashcheniya: 27.05.2015).

7. Dvigayas' v edinom rusle // Rossiiskaya gazeta. 2013. 21 maya. URL: http://www.rg.ru/2013/05/21/pravo.html (data obrashcheniya: 27.05.2015).

8. The Cooperative Approach to Tax Compliance-Revenue Working with Large Business. URL: http://www.revenue.ie/en/ business/running/large-businesses.html (data obrashcheniya: 27.05.2015).

9. Federal'naya nalogovaya sluzhba: sait. URL: www.nalog.ru/html/sites/www.r28.nalog.ru/.../26.12.12.doc (data obrashcheniya: 27.05.2015).

10. Soglashenie o nekom «gorizontal'nom monitoringe» kak novaya forma nalogovogo kontrolya ... prichem ne predusmotrennaya deistvuyushchim nalogovym zakonodatel'stvom // 0 nalogakh i o zhizni: personal'nyi blog Arkadiya Bryzgalina. URL: http://www.nalog-briz.ru/2013/01/blog-post_6516.html (data obrashcheniya: 27.05.2015).

11. Sattarova N.A. Gorizontal'nyi monitoring kak faktor effektivnosti nalogovogo administrirovaniya // Finansovoe pravo. 2014. № 10. S. 24.

12. Il'in A.Yu. Gorizontal'nyi monitoring-novyi metod v sisteme nalogovogo kontrolya // Finansovoe pravo. 2014 . № 10. S. 5.

13. Genzel' V. Praktika primeneniya gorizontal'nogo monitoringa // Nalogovyi vestnik. 2013. № 6. S. 65.

14. Chistyakova L. Nalogovyi monitoring - novaya forma nalogovogo kontrolya v RF // Nalogovyi vestnik. 2014. № 12. S. 18.

15. Vesnitskaya E.G. Znakom'tes': novaya forma nalogovogo kontrolya-nalogovyi monitoring // Aktual'nye voprosy bukhgalterskogo ucheta i nalogooblozheniya. 2015. № 2. S. 64.

16. Gorelov A.A. Formy i metody, ispol'zuemye nalogovymi organami pri osushchestvlenii meropriyatii nalogovogo kontrolya // Administrativnoe i munitsipal'noe pravo. 2008. № 8. S. 77.

17. Nalogovoe pravo. Obshchaya chast': uchebnik i praktikum dlya akademicheskogo bakalavriata / avt. koll. pod. red. I.I. Kucherova. M.: Yurait, 2014. S. 504.

18. O vnesenii izmenenii v chast' pervuyu Nalogovogo kodeksa Rossiiskoi Federatsii: proekt Federal'nogo zakona № 5296306 (red., prinyataya GD FS RF v I chtenii 01.07.2014) // Dostup iz spravochnoi pravovoi sistemy «Konsul'tantPlyus».

19. O vnesenii izmenenii $\mathrm{v}$ chast' pervuyu Nalogovogo kodeksa Rossiiskoi Federatsii: proekt Federal'nogo zakona № 529630-6 (red., podgotovlennaya GD FS RF ko II chteniyu 21.10.2014) // Dostup iz spravochnoi pravovoi sistemy «Konsul'tantPlyus».

20. Sm.: Po proektu Federal'nogo zakona № 529630-6 «0 vnesenii izmenenii v chast' pervuyu Nalogovogo kodeksa Rossiiskoi Federatsii» (pervoe chtenie): zaklyuchenie PU Apparata GD FS RF ot 23.06.2014 № 2.2-1/3447 // Dostup iz spravochnoi pravovoi sistemy «Konsul'tantPlyus»; Po proektu Federal'nogo zakona № 529630-6 «0 vnesenii izmenenii v chast' pervuyu Nalogovogo kodeksa Rossiiskoi Federatsii» (pervoe chtenie): reshenie Komiteta po byudzhetu i nalogam ot 27.06.2014 // Dostup iz spravochnoi pravovoi sistemy «Konsul'tantPlyus».

21. Enhanced Relationship with the Dutch Tax and Customs Administration. URL: http://www.tradeandtax.com/en/ enhanced-relationship/ (data obrashcheniya: 27.05.2015)

22. Efremova T.A., Efremova L.I. Informatsionnoe vzaimodeistvie nalogovykh organov s nalogoplatel'shchikami: deistvuyushchaya praktika i perspektivy razvitiya // Nalogi i nalogooblozhenie. - 2015. - 6. - C. 457 - 464. DOI: 10.7256/1812-8688.2015.6.15265.

23. Irizepova M.Sh., Lomakina T.P. Organizatsiya gosudarstvennogo nalogovogo monitoringa Rossii // Nalogi i nalogooblozhenie. - 2014. - 5. - C. 490 - 500. DOI: 10.7256/1812-8688.2014.5.12198.

24. E.V.NadtochiiGorizontal'nyimonitoring-novyiinstrumentvzaimodeistviya vnalogovoisfere//Nalogiinalogooblozhenie.2013. - 1. - C. 33 - 40. DOI: 10.7256/1812-8688.2013.01.3. 